\title{
IMMUNE RESPONSES IN RAINBOW TROUT (ONCORHYNCHUS MYKISS) FOLLOWING THE ADMINISTRATION OF CELL- MEDIATED AND HUMORAL W/O ADJUVANTED VACCINES POST- VACCINATION AND POST-CHALLENGE
}

\author{
Kimberly A. Veenstra ${ }^{1 \S}$, Lincoln Tubbs ${ }^{2}$, Juliette Ben Arous ${ }^{3}$, Christopher J. Secombes ${ }^{1}$ \\ ${ }^{1}$ Scottish Fish Immunology Research Centre, School of Biological Sciences, University of Aberdeen, \\ Tillydrone Ave., Aberdeen AB24 2TZ, U.K. \\ ${ }^{2}$ ELANCO, Aquaculture Research and Development, P.O. Box 17, Victoria P.E., COA 2G0, CANADA \\ ${ }^{3}$ SEPPIC, Animal Health Division, 22 Terrasse Bellini, Paris La Défense, 92806 Puteaux, FRANCE
}

Adjuvants are the helper substances that increase vaccine efficacy by enhancing the potency and longevity of specific immune responses to antigens. Most existing fish vaccines are presented in the form of oil-based emulsions delivered by intraperitoneal (i.p.) injection which provides a strong and long lasting protection against diseases. However, they are frequently associated with aggressive inflammatory responses resulting in clinically significant side-effects such as melanisation and adhesions. Two in vivo trials were undertaken to develop a deeper understanding of vaccine formulations for fish, by trying to identify and characterize immune responses and side effects resulting from the i.p. administration of two oil adjuvanted-vaccines co-administered with a whole-cell Aeromonas salmonicida bacterin. The first experiment involved one adjuvant thought to induce humoral (Montanide ${ }^{\mathrm{TM}}$ ISA 763A VG) and one to induce cell mediated (Montanide ${ }^{\mathrm{TM}}$ ISA $761 \mathrm{VG}$ ) immune responses in fish. Post-vaccination side effect scoring was followed by the removal of gill, spleen, head kidney and adipose tissue for RTqPCR gene expression analysis, and blood for antibody titres. Fifty immune genes were examined with a focus on a) pro-inflammatory and b) adaptive immune related markers linked with possible $\mathrm{Th}_{1}, \mathrm{Th}_{2}, \mathrm{Th}_{17}$ and $\mathrm{T}_{\text {reg }}$ pathways. Unique immune gene profiles were observed within head kidney, spleen and adipose tissues over time, as well as between humoral and cell mediated adjuvants. A strong up-regulation of pro-inflammatory genes which persisted over time, particularly in adipose tissue, was observed. Side effects were more severe with the cell mediated adjuvant, however there was no significant difference in specific antibody production between the vaccines. In the second experiment, fish vaccinated with Montanide ${ }^{\mathrm{TM}}$ ISA 763A VG and Montanide ${ }^{\mathrm{TM}}$ ISA $761 \mathrm{VG}$ were challenged intraperitoneally eight weeks post-vaccination with A. salmonicida. Twenty-four hours post-challenge spleen and adipose tissue were sampled for RTqPCR gene expression analysis using the fifty immune genes examined in the previous experiment in order to investigate the differences between vaccinated and non-vaccinated fish in response to the live pathogen. The findings from these experiments provide valuable insights into inflammatory and adaptive immune responses in fish following vaccination and will hopefully allow development of protocols enabling the rapid screening of novel vaccine adjuvant formulations in the future.

Keywords: rainbow trout, gene expression, vaccine, adjuvant, challenge

${ }^{\S}$ Corresponding author. Tel.: +44 (0)1224 273270 
Email address: k.veenstra@abdn.ac.uk 